\title{
DISASTER MITIGATION TRAINING (PELATIHAN MITIGASI BENCANA) UNTUK ANAK USIA DINI DI MUHAMMADIYAH BOARDING SCHOOL SANG SURYA, KOTA MATARAM
}

\author{
Hidayati $^{1}$, Rima Rahmaniah ${ }^{1)}$, M Hudri $^{1}$, Irwandi $^{1}$, Moh Fauzi Bafadal ${ }^{1)}$ \\ 1)Program Studi Pendidikan Bahasa Inggris, FKIP, Universitas Muhammadiyah Mataram, Mataram, Indonesia \\ Corresponding author: Hidayati \\ E-mail : hidayatinail73@gmail.com
}

Diterima 29 April 2020, Disetujui 8 Mei 2020

\begin{abstract}
ABSTRAK
Penyelenggaraan penanggulangan bencana dalam situasi terdapat potensi terjadi bencana sebagaimana dimaksud dalam Pasal 34 huruf b meliputi kesiap siagaan, peringatan dini dan mitigasi bencana (UndangUndang Republik Indonesia Nomor 24,2007 tentang Penanggulangan Bencana). Mitigasi bencana adalah serangkaian upaya untuk mengurangi resiko bencana, baik melalui pembangunan fisik maupun penyadaran dan peningkatan kemampuan menghadapi bencana, mitigasi bencana merupakan suatu aktivitas yang berperan sebagai tindakan pengurangan dampak bencana atau usaha-usaha yang dilakukan untuk mengurangi korban ketika bencana terjadi baik korban jiwa maupun harta. Besarnya potensi ancaman bencana di Indonesia menyebabkan peluang masyarakat menjadi korban sangat besar terutama anak-anak dikarenakan mereka masih sangat rentan dan memiliki pengetahuan yang minim berkaitan dengan mitigasi bencana. Pemberdayaan anak usia sejak dini untuk memahami mitigasi bencana merupakan langkah awal membangun masyarakat sadar bencana sehingga ketika terjadi bencana maka partisipan PKM yaitu guru dan anak-anak usia dini di MBS Sang Surya yang berada ditempat ini tidak lagi kebingungan dan panik karena telah memahami bagaimana cara mengatasi dan mengurangi resiko bencana. Dengan harapan pengetahuan yang didapat selama PKM ini ditularkan pada lingkungan sekitar dalam rangka mengurangi risiko bencana, maka metode observasi partisipatoris atau observasi partisipan dan role play atau metode praktik dipergunakan dalam PKM ini. Kegiatan ini dalam pelaksanaannya juga melibatkan tenaga ahli dan Komunitas Relawan Mataram (KRM) yang juga tergabung dalam Muhammadiyah Disaster Management Centre (MDMC) Nusa Tenggara Barat. Hasil capaian dan kesimpulan dalam kegiatan ini sebagai berikut: a) Telah adanya pengetahuan dan pemahaman tentang mitigasi bencana sehingga setiap tindakan bertujuan untuk meningkatkan self awareness mereka tentang bencana yang potensial terjadi, dan b) Dimilikinya pengetahuan kesiapsiagaan akan mitigasi bencana yang bertujuan untuk mengatasi dan mengurangi dampak bencana atau resiko jangka panjang terhadap harta dan jiwa manusia.
\end{abstract}

Kata kunci: mitigasi; bencana; anak usia dini.

\begin{abstract}
Implementation of disaster management in potential situations as referred to in Article 34 letter b includes preparedness, early warning and disaster mitigation (Law of the Republic of Indonesia Number 24,2007 concerning Disaster Management). Disaster mitigation is a series of efforts to reduce the risk of disasters, both through physical development and awareness raising and capacity to deal with disasters, disaster mitigation is an activity that acts as an action to reduce the impact of disasters or efforts made to reduce casualties when disasters occur both casualties and treasure. The magnitude of the potential threat of disasters in Indonesia causes the opportunity for the community to become very large victims especially children because they are still very vulnerable and have minimal knowledge related to disaster mitigation. Empowerment of children from an early age to understand disaster mitigation is the first step in building a community aware of disasters occurs, PKM participants are teachers and early children in MBS Sang Surya who are in this place are no longer confused and panicked because they have understood how to overcome and reduce disaster risk. With the expectation that knowledge gained during PKM is transmitted to the surrounding environment in order to reduce disaster risk, participatory observation methods or participant observation and role play or practice methods are used. This activity in its implementation also involved experts and the Mataram Volunteer Community (KRM) who were also members of the West Nusa Tenggara Muhammadiyah Disaster Management Center (MDMC). The results and achievements in this activity are
\end{abstract}


as follows: a\} Knowledge and understanding of disaster mitigation has been created so that every action aims to increase their self-awareness about potential disasters, and b) Possess knowledge of disaster preparedness aimed at mitigating and reducing the impact of disasters or long-term risks on human assets and lives

Keywords: mitigation; disaster; early children.

\section{PENDAHULUAN}

Bencana adalah peristiwa atau rangkaian peristiwa yang mengancam dan mengganggu kehidupan serta penghidupan masyarakat yang disebabkan oleh faktor alam dan atau factor non alam. Indonesia merupakan negeri dengan potensi bencana alam sangat tinggi khususnya untuk bencana gempa bumi, letusan gunung berapi, dan Tsunami karena terletak pada pertemuan tiga lempeng/kerak bumi aktif. Adapun kepulauan Indonesia termasuk dalam wilayah Pacific Ring of Fire (deretan gunung berapi Pasifik) yang bentuknya melengkung dari utara pulau Sumatera-Jawa-Nusa Tenggara hingga ke Sulawesi Utara, kepulauan Indonesia juga terletak di pertemuan dua lempeng tektonik dunia dan dipengaruhi oleh tiga gerakan, yaitu Gerakan Sistem Sunda di bagian barat, Gerakan Sistem pinggiran Asia Timur dan Gerakan Sirkum Australia, kedua faktor tersebut menyebabkan Indonesia rawan terhadap bencana khususnya letusan gunung berapi dan gempa bumi (Oktarina:2008).

Sedangkan gempa bumi adalah getaran atau guncangan yang terjadi di permukaan bumi. Gempa bumi disebabkan oleh terjadinya pergerakan lempeng bumi. Kebanyakan gempa bumi disebabkan dari pelepasan energi yang dihasilkan oeh tekanan yang dilakukan oleh lempengan yang bergerak. Semakin lama tekanan itu kian membesar dan akhirnya mencapai keadaan dimana tekanan tersebut tidak dapat ditahan lagi pergerakannya. Beberapa kasus bencana alam terkini terjadinya gempa bumi di provinsi NTB yang mengakibatkan banyak korban, serta beberapa guncangan yang terjadi di daerah Banten yang berimbas pula di daerah DKI Jakarta.

Penyelenggaraan penanggulangan bencana dalam situasi terdapat potensi terjadi bencana sebagaimana dimaksud dalam Pasal 34 huruf $b$ meliputi kesiap siagaan, peringatan dini dan mitigasi bencana (Undang-Undang Republik Indonesia Nomor 24,2007 tentang Penanggulangan Bencana). Mitigasi bencana adalah serangkaian upaya untuk mengurangi resiko bencana, baik melalui pembangunan fisik maupun penyadaran dan peningkatan kemampuan menghadapi bencana, mitigasi bencana merupakan suatu aktivitas yang berperan sebagai tindakan pengurangan dampak bencana atau usaha-usaha yang dilakukan untuk mengurangi korban ketika bencana terjadi baik korban jiwa maupun harta (Pusat Pendidikan Mitigasi Bencana:2010). Mitigasi sendiri diartikan sebagai setiap tindakan yang berkelanjutan yang dilakukan untuk mengurangi atau menghilangkan resiko jangka panjang terhadap harta dan jiwa manusia, dalam kaitan ini, mitigasi dapat dikatakan sebagai sebuah mekanisme agar masyarakat dapat menghindari dampak dari bencana yang potensial terjadi (Damayanti, 2010).

Negara Indonesia memiliki potensi bencana yang sangat besar sehingga masyarakat harus memahami proses mitigasi bencana yang baik. Besarnya potensi ancaman bencana di Indonesia menyebabkan peluang masyarakat menjadi korban sangat besar terutama anak-anak dikarenakan anak-anak masih sangat rentan dan memiliki pengetahuan yang minim berkaitan dengan mitigasi bencana. Secara umum, praktek mitigasi dapat dikelompokkan ke dalam mitigasi struktural dan mitigasi non struktural. Mitigasi struktural berhubungan dengan usaha-usaha pembangunan konstruksi fisik, sementara mitigasi non struktural antara lain meliputi perencanaan tata guna lahan, memberlakukan peraturan pembangunan, dan melalui pendidikan untuk menyiapkan masyarakat membiasakan diri hidup bersama dengan bencana, khususnya untuk lingkungan yang sudah terlanjur terbangun, sehingga masyarakat dapat merasakan keamanan dan kenyamanan dalam hidupnya (Rusilowati:51-60). Dari kesimpulan diatas dapat dikatakan bahwa mitigasi bencana adalah suatu usaha untuk masyarakat agar menyadari terjadinya bencana dan dapat menghindari dampak berbahaya dari bencana yang terjadi dengan melakukan kegiatan penanggulangan bencana dan kesadaran akan bencana.

Maka dari itu tim pelaksana membuat pengabdian yang bertujuan untuk mensosialisasikan dan melatih kesadaran tanggap bencana gempa bumi sejak anak usia 
dini. Mitigasi bencana ini bertujuan untuk mengajarkan anak paham kesadaran terhadap bencana alam yang terjadi. Pendidikan Anak Usia Dini (PAUD) bukan hanya sekedar mempersiapkan anak untuk masuk ke Sekolah Dasar, fungsi PAUD yang sebenarnya adalah untuk mengembangkan semua potensi yang dimiliki anak dan melekatkan dasar kearah perkembangan sikap, pengetahuan, ketrampilan dan daya cipta untuk menyesuaikan diri dengan lingkungannya dan untuk pertumbuhan dan perkembangan selanjutnya. Pemberdayaan anak usia sejak dini untuk memahami mitigasi bencana merupakan langkah awal membangun masyarakat sadar bencana sehingga ketika terjadi bencana guru dan anak-anak usia dini ditempat ini tidak lagi kebingungan dan panik karena telah memahami bagaimana cara mengurangi risiko bencana. Dengan harapan pengetahuan yang didapat ditularkan pada lingkungan sekitar dalam rangka mengurangi risiko bencana.

Maka guna mengurangi dampak bencana di atas, maka para dosen program studi Pendidikan Bahasa Inggris bersama mahasiswa yang kemudian disebut sebagai tim pelaksana pengabdian bersama melaksanakan kegiatan sosialisasi dan pelatihan mitigasi bencana dan penanggulangannya pada anak usia dini di Muhammadiyah Boarding School (MBS) Sang Surya, Kota Mataram. Pada kegiatan tersebut, akan diberikan pemaparan mengenai mitigasi bencana, seperti pemutaran video atau film animasi bencana dimana video yang ditayangkan adalah diproduksi oleh Lembaga Penanggulangan Bencana (MDMC) pada tahun 2017 tentang bencana Tsunami, bencana longsor, dan gempa bumi, kegiatan ini kemudian dilanjutkan dengan sesi tanya jawab dan quiz mengenai kejadian bencana yang terjadi di Indonesia yang terdapat pada video yang ditayangkan untuk meningkatkan self awareness anak.

\section{METODE PENELITIAN}

Kegiatan ini telah dilakukan selama 12 (dua belas) pekan dalam 3 (tiga) bulan dengan menggunakan metode observasi partisipatoris atau observasi partisipan adalah suatu proses pengamatan yang dilakukan oleh observer dengan ikut mengambil bagian dalam kehidupan orang-orang yang akan diobservasi, metode praktik langsung adalah metode yang dilakukan oleh guru dengan cara melakukan praktek secara langsung sesuai dengan materi yang akan disampaikan kepada anak-anak.
Dalam pelaksanaan kegiatan pengabdian pada masyarakat ini tim pelaksana pengabdian pada masyarakat ini bermitra dengan Muhammadiyah Boarding School (MBS) Sang Surya dengan melibatkan para guru, tenaga pendamping dan anak-anak usia dini di taman kanak-kanak (kindergarten), kelompok bermain (playgroup), dan taman penitipan (day care) yang berusia 3-6 tahun. Lokasi Muhammadiyah Boarding School (MBS) Sang Surya ini di jalan Merdeka Raya Batu Ringgit Mataram di desa Batu Ringgit Kecamatan Sekarbela Kotamadya Mataram. Sekolah ini berdiri sejak tahun 2017 dan mulai beroperasi awal tahun 2018 dengan jumlah guru dan pendamping sebanyak 13 orang dan memiliki anak-anak usia dini berkisar usia 2 - 7 tahun sebanyak kurang lebih 50 (lima puluh) orang sampai saat tim pengabdian melaksanakan kegiatannya. Di bawah ini adalah tahapan pelaksanaan kegiatan pengabdian pada masyarakat yang dilaksanakan oleh tim pelaksanan pengabdian yang terdiri dari kolaborasi antara dosen dan mahasiswa program studi Pendidikan Bahasa Inggris FKIP UMMAT. Tahapan dari pelaksanaan kegiatan teknis yang dilaksanakan dalam kegiatan PKM dijabarkan sebagai berikut:

1. Surat menyurat khususnya perijinan kepada pihak pengelola dan kepala sekolah MBS Sang Surya terkait waktu dan jadwal kegiatan pengabdian pada masyarakat ini yang mana pelaksanaan kegiatan dilaksanakan pada bulan Oktober sampai Desember 2019 selama 3 (tiga) bulan.

2. Melakukan sosialisasi sesuai jadwal yang telah ditentukan yaitu dimulai pada pekan ke-4 yaitu dengan memutar video dengan judul "Film Anak Siaga Bencana" yang nerupakan video animasi yang diproduksi dan dirilis oleh Lembaga Penanganan Bencana Muhammadiyah Disaster Management Center (MDMC) Pusat yang dipublikasi sejak tahun 2017.

3. Melakukan pelatihan pada pekan ke-5 - 10 tentang mitigasi bencana khususnya bencana gempa bumi pada guru dan anakanak usia dini di Muhammadiyah Boarding School (MBS) Sang Surya, Kota Mataram dengan melakukan pemaparan mengenai mitigasi bencana, pada saat sebelum bencana, ketika erjadi bencana dan setelah bencana terjadi pada bencana longsor, dan gempa bumi yang telah dilakukan pada acara sosialisasi sebelumnya, praktik kegiatan AO Ninja disaat terjadi bencana Gempa, sesi tanya jawab dan quiz mengenai 
kejadian bencana yang terjadi di Indonesia untuk meningkatkan self awareness anak disertai dengan pemberian reward pada anak-anak yang dapat menjawab pertanyaan dan dapat melakukan kegiatan dengan benar sesuai arahan tim pengabdian kepada masyarakat.

4. Dan melakukan evaluasi terhadap pelaksanaan Pelatihan Mitigasi Bencana pada anak-anak tersebut untuk melihat keberhasilan target yang diharapkan dalam kegiatan PKM ini.

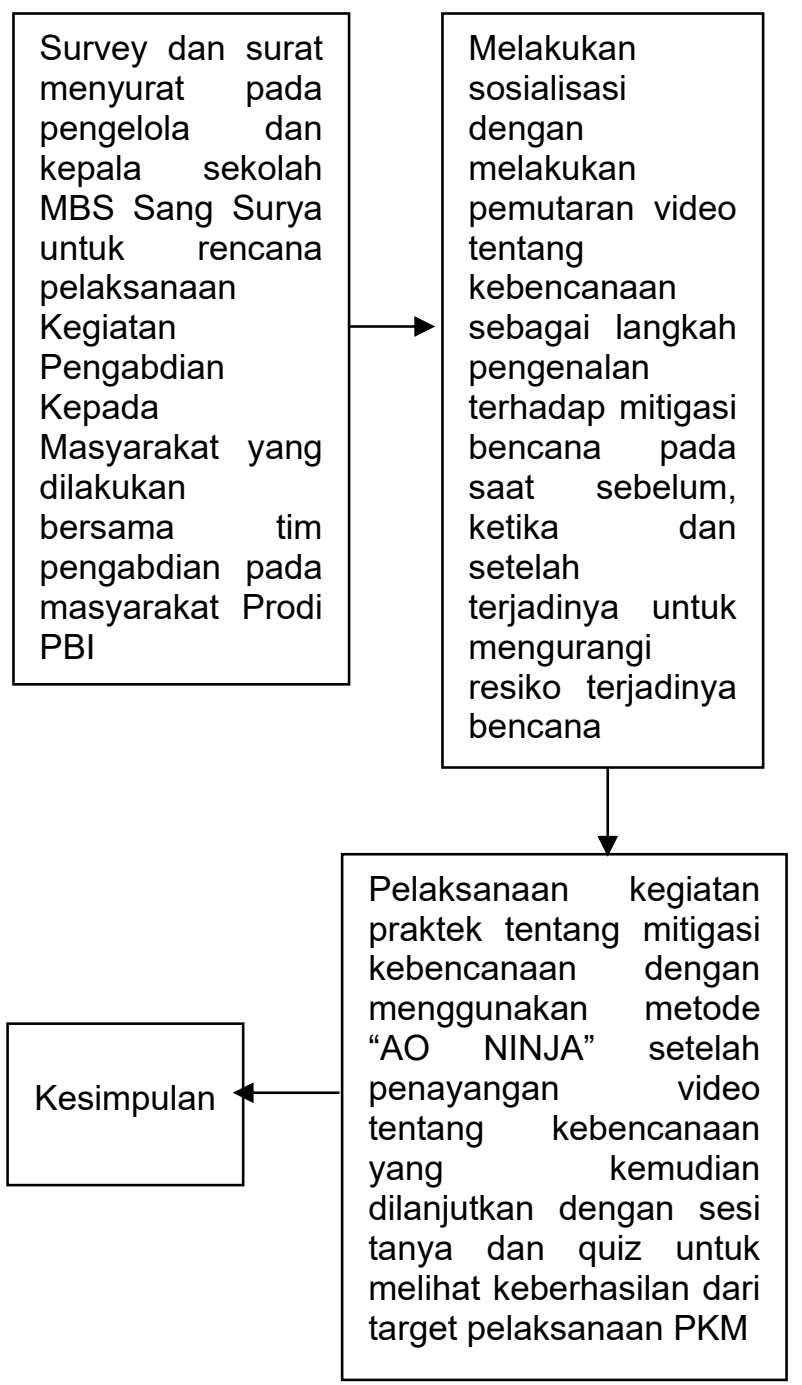

Gambar 1. Tahap Pelaksanaan Kegiatan PKM

\section{HASIL DAN PEMBAHASAN}

Bencana adalah peristiwa atau rangkaian peristiwa yang mengancam dan mengganggu kehidupan serta penghidupan masyarakat yang disebabkan oleh faktor alam dan atau faktor non alam. Indonesia merupakan negeri dengan potensi bencana alam sangat tinggi khususnya untuk bencana gempa bumi, letusan gunung berapi, dan Tsunami karena terletak pada pertemuan tiga lempeng/kerak bumi aktif. Adapun kepulauan Indonesia termasuk dalam wilayah Pacific Ring of Fire (deretan gunung berapi Pasifik) yang bentuknya melengkung dari utara pulau Sumatera-Jawa-Nusa Tenggara hingga ke Sulawesi Utara, kepulauan Indonesia juga terletak di pertemuan dua lempeng tektonik dunia dan dipengaruhi oleh tiga gerakan, yaitu Gerakan Sistem Sunda di bagian barat, Gerakan Sistem pinggiran Asia Timur dan Gerakan Sirkum Australia, kedua faktor tersebut menyebabkan Indonesia rawan terhadap bencana khususnya letusan gunung berapi dan gempa bumi.

Sedangkan gempa bumi adalah getaran atau guncangan yang terjadi di permukaan bumi. Gempa bumi disebabkan oleh terjadinya pergerakan lempeng bumi. Kebanyakan gempa bumi disebabkan dari pelepasan energi yang dihasilkan oeh tekanan yang dilakukan oleh lempengan yang bergerak. Semakin lama tekanan itu kian membesar dan akhirnya mencapai keadaan dimana tekanan tersebut tidak dapat ditahan lagi pergerakannya. Beberapa kasus bencana alam terkini terjadinya gempa bumi di provinsi NTB yang mengakibatkan banyak korban, serta beberapa guncangan yang terjadi di daerah Banten yang berimbas pula di daerah DKI Jakarta. Bencana gempa yang terjadi di provinsi NTB ini mencapai 7 skala richter yang terjadi pada akhir bulan Juli sampai dengan bulan Nopember tahun 2018 dimana hal ini mengakibatkan banyaknya korban jiwa dan harta dari bencana gempa yang terjadi ini khususnya di pulau Lombok. Oleh karena itu, maka mitigasi bencana amat sangat diperlukan diberikan pada masyarakat yang memang daerahnya potensial terjadi bencana.

Mitigasi Bencana adalah serangkaian upaya untuk mengurangi resiko bencana, baik melalui pembangunan fisik maupun penyadaran dan peningkatan kemampuan menghadapi bencana. Mitigasi bencana merupakan suatu aktivitas yang berperan sebagai tindakan pengurangan dampak bencana atau usahausaha yang dilakukan untuk mengurangi korban ketika bencana terjadi baik korban jiwa maupun harta. Mitigasi sendiri diartikan sebagai setiap tindakan yang berkelanjutan yang dilakukan untuk mengurangi atau menghilangkan resiko jangka panjang terhadap harta dan jiwa manusia, dalam kaitan ini, mitigasi dapat dikatakan sebagai sebuah mekanisme agar masyarakat dapat menghindari dampak dari bencana yang 
potensial terjadi. Adapun yang dilakukan dalam PKM ini, bertujuan agar anak yang secara definisi adalah korban yang paling rentan atas dampak bencana menjadi memiliki kesiapsiagaan atas bencana yang terjadi di sekitarnya atau memiliki sikap self awareness untuk selalu berpikir tentang bagaimana mengurangi atau membatasi resiko terjadinya bencana baik harta maupun korban jiwa.

Tujuan dari kegiatan mitigasi bencana yang dilakukan yaitu: a) Mengurangi dampak yang ditimbulkan, khususnya bagi penduduk, b) Sebagai landasan (pedoman) untuk perencanaan pembangunan, dan c) Meningkatkan pengetahuan masyarakat dalam menghadapi serta mengurangi dampak/resiko bencana, sehingga masyarakat dapat hidup dan bekerja dengan aman. Dalam kegiatan mitigasi bencana gempa bumi yang dilakukan pada anak-anak usia dini ini para tim pelaksana pengabdian bermitra dengan Muhammadiyah Boarding School (MBS) Sang Surya yang melibatkan semua guru, tenaga pendamping dan anak-anak usia dini yang berusia antara 3-6 tahun, dimana dalam kegiatan PKM ini, pengethauan dana pemahaman yang diberikan mencakup kegiatan sebelum, ketika dan setelah gempa dengan pemaparan materi mitigasi bencana dengan cara memutarkan video animasi anak "Aku Anak Siaga" dimana video ini memang telah diproduksi dan dirilis pada tahun 2017 oleh Lembaga Pengangan Bencana Muhammadiyah Disaster Management Center (MDMC) Pusat Muhammadiyah. Adapun hal-hal yang dilakukan berdasarkan tahapan pada video di atas sebagai berikut:

a) Sebelum bencana gempa terjadi

- Tempatkan perabotan pada tempat yang proporsional

- Siapkan peralatan seperti senter, P3K, makanan instan, dll

- Catat nomor telepon penting

- Kenali jalur evakuasi

- Ikuti kegiatan simulasi mitigasi bencana gempa

b) Ketika Gempa

- Tetap tenang

- Hindari sesuatu yang kemungkinan akan roboh, kalau bisa ke tanah lapang

- Perhatikan tempat berdiri, kemungkinan ada retakan tanah

- Turun dari kendaraan dan jauhi pantai.

c) Setelah Gempa
- Cepat keluar dari bangunan. Gunakan tangga biasa

- Periksa sekitar kita. Jika ada yang terluka, lakukan pertolongan pertama

- Hindari bangunan yang berpotensi roboh

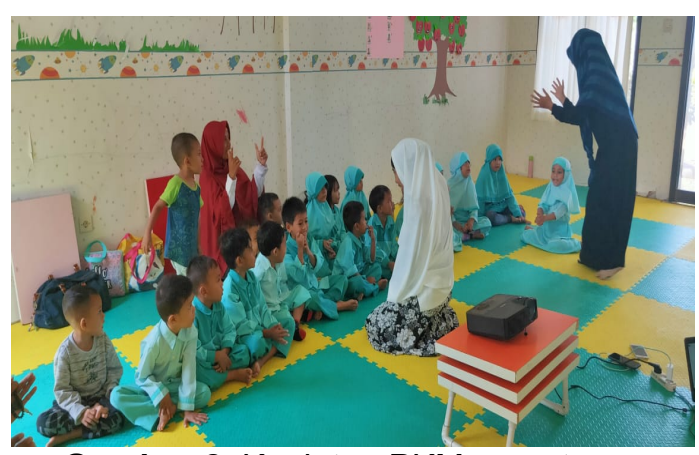

Gambar 2. Kegiatan PKM pemutaran video "Film Aku Anak Siaga Bencana"

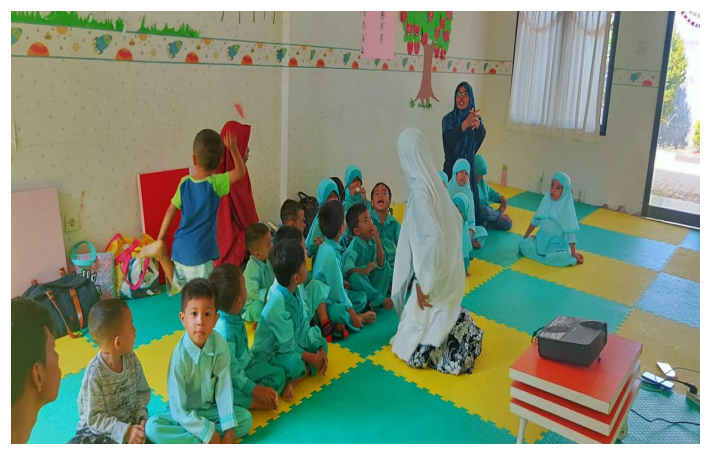

Gambar 3. Kegiatan praktik dan sesi tanya jawab setelah pemutaran video animasi yang berjudul "Film Aku Anak Siaga Bencana"

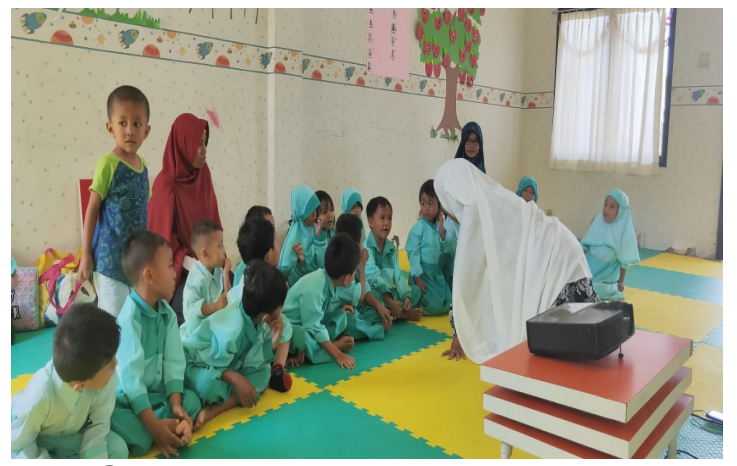

Gambar 4. Kegiatan quiz setelah pemutaran video "Film Anak Siaga Bencana" 


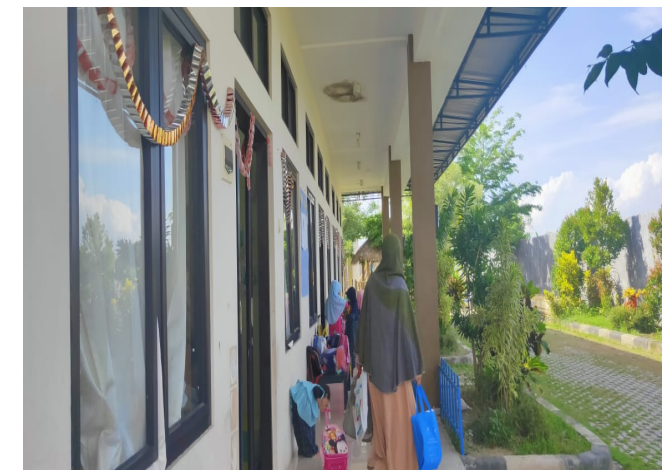

Gambar 5. Kegiatan praktek dan sekaligus evaluasi kegiatan PKM

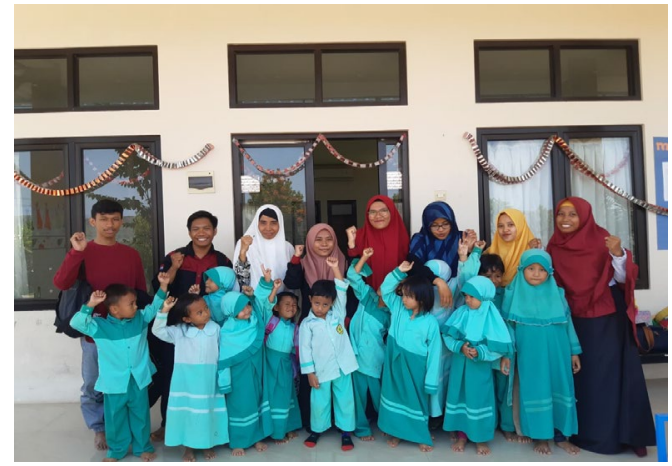

Gambar 6. Praktek sekaligus evaluasi kegiatan PKM

Dalam kegiatan PKM ini, para tim pengabdian terakhir melakukan evaluasi untuk melihat sejauhmana keberhasilan akan target pencapaian yang dilakukan dengan melaksanakan praktek di lapangan dengan menggunakan beberapa peralatan sederhana seperti menggantung benda di atas pintu sebagai penanda sebelum erjadi bencana gempa, penunjuk jalur evakuasi, telpon dan hape untuk menelpon tim rescue dan beberpa lainnya untuk melakukan simulasi mitigasi bencana yang sudah diberikan dalam beberapa kali pertemuan. Kegiatan ini paling disenangi anak-anak karena mereka bisa aktif berpartisipasi dalam kegiatan mitigasi bencana bersama guru, pendamping dan tim pelaksana pengabdian. Sehingga dapat dikatakan dengan kegiatan pelatihan mitigasi bencana ini diharapkan tujuan agar anak-anak usia dini dapat mengembangkan semua potensi yang dimiliki anak dan melekatkan dasar kearah perkembangan sikap, pengetahuan, ketrampilan dan daya cipta untuk menyesuaikan diri dengan lingkungannya dan untuk pertumbuhan dan perkembangan selanjutnya. Pemberdayaan anak usia sejak dini untuk memahami mitigasi bencana merupakan langkah awal membangun masyarakat sadar bencana sehingga ketika terjadi bencana guru dan anak-anak usia dini ditempat ini tidak lagi kebingungan dan panik karena telah memahami bagaimana cara mengurangi risiko bencana. Dengan harapan pengetahuan yang didapat ditularkan pada lingkungan sekitar dalam rangka mengurangi resiko bencana.

\section{SIMPULAN DAN SARAN Simpulan}

Bencana gempa yang pernah terjadi pada sekitar bulan Juli sampai dengan bulan Nopember tahun 2018 lalu di pulau Lombok dengan kekuatan 7 skala richter yang mengakibatkan banyaknya korban jiwa dan harta tersebut telah menginisasi tim pelaksana pengabdian pada masyarakat program studi Pendidikan Bahasa Inggris mengadakan pelatihan mitigasi bencana khususnya mitigasi bencana gempa dengan melibatkan tenaga ahli dan Komunitas Relawan Muhammadiyah yang bertujuan untuk memberikan pengetahuan dan pemahaman pada anak-anak usia dini tentang kesiapsiagaan terhadap bencana yang potensial terrjadi di wilayah dan lingkungan sekitarnya. Kegiatan ini bermitra dengan Muhammadiyah Boarding School (MBS) Sang Surya Kota Mataram dimana para guru, tenaga pendamping dan anak-anak usia dini menjadi partisipan dalam kegiatan pelatihan ini. Simpulan yang kemudian dapat ditarik setelah kegiatan PKM ini terlaksana adalah sebagai berikut:

a) Telah adanya pengetahuan dan pemahaman tentang mitigasi bencana sehingga setiap tindakan bertujuan untuk meningkatkan self awareness mereka tentang bencana yang potensial terjadi, dan

b) Dimilikinya pengetahuan kesiapsiagaan akan mitigasi bencana yang bertujuan untuk mengatasi dan mengurangi dampak bencana atau resiko jangka panjang terhadap harta dan jiwa manusia.

\section{Saran}

Saran yang dapat diberikan untuk perbaikan dan kemaslahatan bersama kedepan adalah hendaknya memang telah menjadi tugas dan tanggungjawab para tenaga ahli yang dalam hal ini pemerintah untuk selalu dapat mensosialisaikan dan memberikan pengetahuan dan pemahaman pada masyarakat khususnya di pulau Lombok dan Provinsi Nusa Tenggara Barat akan pentingnya sebuah mekanisme tindakan dalam menghadapi bencana yang terjadi. Sebagai gambaran bahwa sebenarnya Indonesia merupakan negeri dengan potensi bencana alam 
yang sangat tinggi khususnya untuk bencana gempa bumi, letusan gunung berapi, dan Tsunami karena terletak pada pertemuan tiga lempeng/kerak bumi aktif. Adapun kepulauan Indonesia termasuk dalam wilayah Pacific Ring of Fire (deretan gunung berapi Pasifik) yang bentuknya melengkung dari utara pulau Sumatera-Jawa-Nusa Tenggara hingga ke Sulawesi Utara, kepulauan Indonesia juga terletak di pertemuan dua lempeng tektonik dunia dan dipengaruhi oleh tiga gerakan, yaitu Gerakan Sistem Sunda di bagian barat, Gerakan Sistem pinggiran Asia Timur dan Gerakan Sirkum Australia, kedua faktor tersebut menyebabkan Indonesia rawan terhadap bencana khususnya letusan gunung berapi dan gempa bumi. Oleh karena itu, kegiatan Mitigasi bencana ini sangat perlu dilakukan secara simultan dan berkelanjutan agar masyarakat menjadi siapsiaga jika bencana terjadi dengan tujuan untuk mengurangi esiko bencana yaitu korban jiwa dan harta.

\section{DAFTAR RUJUKAN}

DP2M Dikti. (2017). Buku Panduan Pelaksanaan Penelitian dan Pengabdian Kepada Masyarakat Edisi XI Tahun 2017. Jakarta.

Flurentin, Elia. (2014). Latihan Kesadaran Diri (Self Awareness) Dan Kaitannya Dengan Penumbuhan Karakter. Jurnal Inspirasi Pendidikan Universitas Kanjuruhan Malang, Vol 1(1). Hal. 9

Harsono. (1988). Coaching Dan Aspek-Aspek Dalam Coaching. Jakarta: Departemen Pendidikan dan Kebudayaan,

LPM UM Mataram. (2018). Pedoman Pengabdian Kepada Masyarakat dan Prosedur Penulisan Proposal. Universitas Muhammadiyah Mataram

Morin, Alain. (2011). Self-Awareness Part 1: Definition, Measures, Effects, Functions, and Antecedents. Mount Royal University Social and Personality Psychology Compass $5 / 10$

Ningtyas, Dhita Paranita. (2018). Pengembangan Permainan Sirkuit Mitigasi Bencana Gempa Bumi Untuk Meningkatkan Self Awareness Anak Usia Dini. Jurnal Caksana-Pendidikan Anak Usia Dini. Volume 1 No 2 Desember 2018. Universitas Trilogi

Oktarina, Riena. (2008). Pemetaan Sistem Informasi Manajemen Logistik dalam Penanggulangan Bencana Di Indonesia, SNATI.
Putra, Hijrah Purnama dan Aditya, Reza. (2014). Pelatihan Mitigasi Bencana Kepada Anak Anak Usia Dini. Jurnal Inovasi dan Kewirausahaan. 3(2), 115-119

Rusilowati, A., Supriyadi. (2012). Mitigasi Bencana Alam Berbasis Pembelajaran Bervisi Science Environment Technology And Society. Jurnal Pendidikan Fisika Indonesia, 8(1), 51-60.

Arsyad, Azhar. (1995). Media Pendidikan. Jakarta: CV Rajawali.[Buku]

Handrianto. (2007). "Pengaruh penggunaan animasi dan video terhadap prestasi belajar sains fisika siswa kelas 1 SMP Negeri 15 Mataram tahun pelajaran 2007/2008". Skripsi Program Studi Pendidikan Fisika. Universitas Mataram.

Herbert, Riza, L. S, and Mukmin, A., (2011). "Penerapan Jaringan Saraf Tiruan Backpropagation Untuk Peramalan Curah Hujan", Teknologi Informasi dan Komunikasi, 1(1), 1-5.

Sektor Pertanian. (2011). Kajian Risiko dan Adaptasi Terhadap Perubahan Iklim Pulau Lombok Provinsi Nusa Tenggara Barat, Dinas Pertanian NTB, Mataram.

Mac Leod, D. (1992). Post-Modernism and Urban Planning. Dipetik June 25, 2010, darihttp://www3.sympatico.ca/david.macl eod/POMO.HTM. 